\title{
A FORMAÇÃO MATEMÁTICA NA PEDAGOGIA: A ARTICULAÇÃO UNIVERSIDADE- ESCOLA COMO CAMINHO FORMATIVO
}

\author{
PROFESSIONAL TRAINING IN MATHEMATICS IN PEDAGOGY: THE UNIVERSITY-SCHOOL RELATIOSHIP AS A TRAINING PATH
}

FORMACIÓN PROFESIONAL EN MATEMÁTICAS EN LA PEDAGOGÍA: LA RELACIÓN UNIVERSIDAD-ESCUELA COMO CAMINO FORMATIVO

AZERÊDO, Maria Alves de ${ }^{1}$

\begin{abstract}
RESUMO
Considerando que a formação matemática na Pedagogia apresenta lacunas, o objetivo deste artigo é o de problematizar as possibilidades de se formar para a docência em Matemática por meio de um projeto voltado à Licenciatura. Embasando-se em autores que discutem formação docente em matemática e na pesquisa qualitativa, analisou-se um relato de uma sequência didática sobre multiplicação, numa turma de $5^{\circ}$ ano e dados de um questionário aplicado aos graduandos. Concluiu-se que as atividades do projeto têm ampliado a formação docente em matemática ao possibilitar a vivência em salas de aula, tendo a escola pública também como espaço formativo, articulando teoria e prática.
\end{abstract}

Palavras-chave: Formação docente. Pedagogia. Matemática. Universidade-escola.

\section{ABSTRACT}

Considering that mathematics as a professional training in a Pedagogy course has gaps, our objective is to problematize the possibilities to create an undergraduate course to teach mathematics through a project directed to this undergraduate degree. Based on authors who discuss teacher training in mathematics as well as based on qualitative research, a report of a didactic sequence on multiplication was analyzed in a 5th grade class and, also, data from a questionnaire applied to undergraduate students. It was concluded that the project activities have expanded the teacher training in mathematics, by enabling the experience in classrooms, having the public school as a formative space, connecting theory and practice.

Keywords: Teacher training. Pedagogy. Mathematics. University-school.

\section{RESUMEN}

Considerando que la formación profesional en matemáticas en la pedagogía presenta lagunas, el objetivo de este artículo es el de problematizar las posibilidades de formarse en docencia Matemática por medio de un proyecto dirigido hacia la Licenciatura. Basándose en autores que discuten formación docente en matemática y en la investigación cualitativa, se analizó un relato de una secuencia didáctica sobre multiplicación, en una clase de 5to año y en datos de un cuestionario aplicado a los graduandos. Se concluyó que las actividades del proyecto han ampliado la formación docente en matemática al posibilitar la vivencia en salas de clase, teniendo a la escuela pública también como espacio formativo, relacionando teoría y práctica.

Palabras clave: Formación docente. Pedagogía. Matemáticas. Universidad-escuela.

\footnotetext{
${ }^{1}$ Universidade Federal da Paraíba - UFPB - João Pessoa - Paraíba - Brasil.
} 


\section{INTRODUÇÃO}

Discutir a formação matemática no curso de Pedagogia é ainda urgente e se justifica, principalmente, por duas razões: os baixos índices de desempenho de alunos de escolas públicas (BRASIL, 2017; 2018) e a relação problemática de professores de anos iniciais com a matemática, advinda de sua trajetória escolar (CARVALHO, 1991; NACARATO; MENGALI; PASSOS, 2009). No entanto, é preciso esclarecer que os cursos de Pedagogia, embora assumam a docência como base, apresentam dificuldades em efetivar esta proposta como seu foco. Ao fazermos uma leitura atual do cenário que envolve este curso, podemos compreender até que ponto a educação matemática tem sido objeto de formação e de pesquisa. Neste trabalho, discutimos as possibilidades de ampliação formativa para estudante na graduação na área de educação matemática, em articulação com a escola pública.

A história dos cursos de Pedagogia no Brasil evidencia que seus objetivos estavam voltados à formação de profissionais especialistas em educação ou técnicos educacionais. Por isso, durante décadas, a formação para a docência na educação infantil e anos iniciais do ensino fundamental esteve a cargo dos cursos em nível médio - Normal - Magistério. Com a exigência da Lei de Diretrizes e Bases da Nacionais da Educação - LDB (BRASIL 1996), para que a formação de professores ocorresse no ensino superior, o Curso de Pedagogia se reestruturou, abarcando esta outra função - a formação de professores para a educação infantil e anos iniciais (GATTI, 2012).

As Diretrizes Curriculares Nacionais dos Cursos de Pedagogia (BRASIL, 2006) assinalam, em seus Art. $2^{\circ}$ e $4^{\circ}$, que a docência é a base da formação, seja "na Educação Infantil e nos anos iniciais do Ensino Fundamental (...), bem como em outras áreas nas quais sejam previstos conhecimentos pedagógicos". Pode-se pensar que o curso apresente um foco, ao evidenciar a docência como base, porém, o documento mantém a formação ainda abrangente do curso ao abranger as áreas de gestão educacional e coordenação pedagógica.

Ao analisar estas diretrizes, Libâneo (2006) tece críticas, afirmando seu caráter ambíguo, reducionista e impreciso. Para ele, a assunção da docência como base da Pedagogia é um dos grandes problemas, pois limita o campo da Pedagogia a uma parte, deste próprio campo, que é a docência. Para o autor, historicamente, compreende-se que todo professor deve ser um pedagogo, mas nem todo pedagogo deve ser professor. Por outro lado, ele critica o caráter generalista do curso ao assumir diferentes funções, não 'dando conta' de nenhuma, com profundidade. O autor destaca, dentre outros problemas, a redução ou ausência "de formação específica de administradores escolares, coordenadores pedagógicos", e também, a "sobrecarga disciplinar no currículo para cobrir todas as tarefas previstas para o professor e a ausência de conteúdos específicos das disciplinas do currículo do ensino fundamental" (LIBÂNEO, 2006, p. 861), embora tenha a docência como base. Entendemos as discussões epistemológicas da Pedagogia enquanto ciência pedagógica, mas nos interessa este último ponto destacado por Libâneo (2006), 'das tarefas previstas para o professor', da docência - seus desafios e possibilidades de contribuição com a escola pública.

Sobre a abrangência do curso, Gatti (2012) afirma que as "instituições de Ensino Superior podem fazer suas escolhas e dirigir melhor essa formação, mas a identidade do curso fica ainda problemática por seu amplo espectro curricular e por suas vocações múltiplas” (p. 7). Mas, em seguida, 
ela destaca "a pouca incorporação de aspectos relativos à Didática e às Práticas de Alfabetização, às Práticas relativas ao ensino de outras disciplinas dos primeiros anos do Ensino Fundamental, e as associadas à Educação Infantil" (GATTI, 2012, p. 158), como problemas para a formação docente.

Pesquisas acerca da docência nos cursos de Pedagogia se constituem relevantes, uma vez que elas têm o papel de formar professores que respondam com qualidade às demandas vindas das escolas. Nesse contexto, este artigo objetiva problematizar as possibilidades de se formar para a docência em matemática, num curso de Pedagogia, por meio de um projeto voltado à licenciatura que busca efetivar uma articulação com escolas públicas, ampliando a formação inicial. O projeto intitulase: Ensinando e Aprendendo Matemática através de Jogos e Resolução de Problemas, o qual contribui na formação de estudantes de Pedagogia, compreendendo a articulação entre a universidade e a escola pública como fundamental à formação de professores.

\section{A FORMAÇÃO MATEMÁTICA DE PROFESSORES DE ANOS INICIAIS}

Os processos de formação docente implicam a apropriação de diferentes conhecimentos e habilidades para o seu trabalho. Ensinar não é uma tarefa simples, principalmente nos contextos atuais, diante da massificação de informações pela internet, da variedade de interesses frente à escola, bem como à diversidade e heterogeneidade em cada sala de aula, tanto no que se referem à cultura quanto aos níveis de conhecimento (LIBÂNEO, 2000; MOREIRA; CANDAU, 2007; GATTI, 2012).

Nessa direção, a formação de professores é desafiada a tomar como ponto de partida, a compreensão de seu campo profissional. Para Tardif (2000), nas últimas décadas, tem-se questionado os modelos de racionalidade instrumental e 'aplicacionista' presentes nos cursos de formação inicial por não partirem da realidade profissional. O profissional professor, a sua prática e os saberes desenvolvidos para tal "não são entidades separadas, mas 'co-pertencem' a uma situação de trabalho na qual 'coevoluem' e se transformam" (TARDIF, 2000, p. 11). Os saberes construídos na formação inicial são parte desse conjunto de saberes, mas não são utilizados de forma direta, na sua prática profissional, e sim, de forma ressignificada e reconstruída.

Os saberes dos professores são plurais e heterogêneos, por serem construídos a partir de diferentes fontes (história de vida, experiência escolar/acadêmica e profissional), e, por sua vez, seu trabalho exige saberes de diferentes ordens: planejar situações didáticas, preparar materiais, ministrar aulas, lidar com os conflitos entre os alunos, motivar a turma para a aprendizagem, avaliar e registrar os processos de ensino, avaliar a aprendizagem dos estudantes (TARDIF, 2000).

Investigando a formação de professores, Shulman (2014) propõe um conjunto de sete conhecimentos necessários para o ensino, desde o conhecimento do conteúdo específico ao conhecimento das finalidades e propósitos da educação. Para ele, o processo formativo inicial deveria incluir:

conhecimento do conteúdo; conhecimento pedagógico geral (...) de gerenciamento e organização de sala de aula (...); conhecimento do currículo, particularmente dos materiais e programas (...); conhecimento pedagógico do conteúdo; conhecimento dos alunos e de suas características; conhecimento de contextos educacionais (...) gestão e financiamento dos sistemas educacionais, até as características das comunidades e suas culturas; e conhecimento 
dos fins, propósitos e valores da educação e de sua base histórica e filosófica (SHULMAN, 2014, p. 206, grifos nossos).

O autor contrapõe-se à ideia de simplificação atribuída ao trabalho do professor, como se fosse necessário apenas o conhecimento do conteúdo da matéria a ser ensinada. Dentre os sete conhecimentos destacados, o conhecimento pedagógico do conteúdo assume uma primazia por conseguir aglutinar a matéria específica a ensinar e os processos pedagógicos, o que é muito presente nos professores em serviço.

Shulman (2014) também ressalta que são quatro, as fontes de construção para o conhecimento de base do professor : 1) a formação acadêmica na disciplina a ensinar; 2) a estrutura e contexto do processo educativo institucionalizado - currículos, programas de avaliação, hierarquias, financiamento; 3) a literatura educativa especializada, envolvendo processos de ensino, de aprendizagem e de fenômenos socioculturais que influenciam o fazer docente e, por fim, 4) a prática pedagógica. Especificamente, em relação à formação inicial, incluem-se a compreensão de conteúdos que pertencem a "produção acadêmica histórica e filosófica sobre a natureza do conhecimento" (SHULMAN, 2014, p. 207). Em relação aos conhecimentos da prática profissional, o autor afirma que carecemos de uma história própria da prática pedagógica, com um sistema de registros e de memória dessa experiência.

Referindo-se à Matemática, pesquisas sinalizam para problemas quanto à consolidação do conhecimento necessário para o ensino até o $5^{\circ}$ ano. Curi (2005), ao investigar propostas curriculares do curso de Pedagogia no país, denuncia a perspectiva eminentemente metodológica das disciplinas que envolvem matemática, questionando ainda, a carga horária insuficiente. Estudos mais recentes, de Matos e Lara (2016) e Silva e Burak (2016) sobre pesquisas brasileiras envolvendo a formação matemática na Pedagogia, corroboram as conclusões de Curi (2005) e reafirmam que os cursos de Pedagogia não estão conseguindo dar conta da especificidade da docência, pois com uma carga horária reduzida, não atende às exigências de aprofundamento conceitual e metodológico dos conceitos matemáticos. Especificamente sobre a carga horária de Matemática, Costa, Pinheiro e Costa (2016), estudando os cursos de Pedagogia, no Paraná, concluíram que quase metade se encontra com o nível baixo de tempo dedicado à formação nesta área, de 54 a 90 h/a.

$\mathrm{Na}$ rede pública de Rondonópolis (MT), Lima e Carvalho (2014), investigaram professores sobre os desafios quando ensinam matemática. Sobre a formação, além da carga horária pequena, com ênfase nas metodologias, eles apontaram "o distanciamento entre o que é ensinado no curso e a realidade escolar e a falta de articulação entre teoria e prática (p. 206)". Quanto ao processo de ensinar matemática, as principais dificuldades foram a falta de compreensão profunda de conceitos da área e condições de trabalho, como turmas muito heterogêneas numa organização escolar em ciclos de aprendizagem (LIMA; CARVALHO, 2014).

D’Ambrosio (2005) considera que a fragilidade conceitual é a maior dificuldade dos professores que necessitam ter conhecimento 'profundo' para "descrever a compreensão do aluno, baseando-se numa renegociação de seu próprio conhecimento de matemática” (p. 20), 'desempacotando' seu próprio conhecimento formal da Matemática e dos alunos para compreendê-los a fundo. 
Além disso, para Carvalho (1991) e Nacarato (2010), a maioria dos estudantes de Pedagogia apresenta aversão à Matemática, indicando crenças e concepções construídas ao longo da vida escolar. Conforme Serrazina (2002), as crenças e concepções compõem um conhecimento implícito ligado às vivências pessoais, sendo mais difíceis modificá-las. Para ela, a "formação inicial tem não só de procurar explicitar o conhecimento tácito dos futuros professores, mas tentar que esse conhecimento evolua mediante processos reflexivos que se apoiam no tratamento e resolução de problemas, isto é, na investigação" (p. 13).

Destacamos a complexidade do processo formativo que além de favorecer conhecimentos aprofundados dos objetos matemáticos, suas representações, processos de ensinar e aprender, deve interferir em crenças e concepções sobre a Matemática e seu ensino, já construídos ao longo da escolarização (período pré-profissional) (CURI, 2005).

\section{VISLUMBRANDO POSSIBILIDADES PARA A FORMAÇÃO DOCENTE EM MATEMÁTICA}

Buscando orientar os processos formativos na área de matemática (inicial e continuada), Shulman (2014), Serrazina (2002; 2012) e Llinares e Fernández (2012) nos dão pistas. Entendendo que esta etapa da formação não dará conta de todas as demandas, "o principal objectivo da formação deve ser que os futuros professores se preparem e se envolvam no seu próprio desenvolvimento profissional de modo que o prossigam ao longo da sua carreira" (SERRAZINA, 2002, p. 5).

Para Llinares e Fernández (2012), a formação para a docência em matemática, necessita desenvolver capacidades que estejam vinculadas ao 'ensinar matemáticas'. Para tanto, eles apresentam um sistema de atividades do fazer docente, abrangendo três frentes: organizar o conteúdo matemático para ensiná-lo (o que implica conhecer o conteúdo para selecionar, analisar e propor tarefas e sequências didáticas); analisar e interpretar as produções matemáticas dos alunos (o que inclui o conhecimento sobre teorias de aprendizagem e sobre conceitos e procedimentos de estudante) e gerenciar o conteúdo matemático em sala de aula (o que envolve conhecer os níveis e fases das lições, os processos interativos com formulações de questões, vinculando-se conhecimentos prévios àqueles a serem ensinados).

A formação para a docência em matemática exige que os estudantes se aproximem da prática docente e produzam conhecimento sobre ela, realizando 'tarefas' para alcançar um determinado objetivo, fazendo uso de instrumentos, sejam técnicos (materiais e procedimentos) ou conceituais (construções teóricas) e justificar seu uso (LLINARES; FERNÁNDEZ, 2012).

Os autores sugerem que os processos de formação apresentem ambientes de aprendizagem, nos quais os estudantes tenham a oportunidade de problematizar: conteúdos matemáticos através de resolução de problemas, situações de ensino e gestão de sala em atividades matemáticas e diferentes organizações de conteúdos em atividades propostas. A problematização de conteúdos matemáticos implica a compreensão e o aprofundamento de conceitos a partir de atividades desafiadoras e de investigação. A análise de situações de ensino de matemática exige que o estudante tenha conhecimentos sobre o assunto de matemática na aula e os processos de aprendizagem que ele abarca, articulando assim, concepção de ensino e de aprendizagem da matemática. Por fim, a 
problematização de atividades matemáticas exige conhecimentos acerca do currículo, da organização da matéria a ser ensinada e dos diferentes níveis cognitivos que as tarefas demandam (se memorização, realização de procedimentos sem conexões, com conexões ou atividades mais complexas que requeiram investigação) (LLINARES; FERNÁNDEZ, 2012).

Aproximando-se dessas propostas, mas voltando-se aos anos iniciais, Serrazina (2002; 2012) afirma que a formação inicial precisa ser um espaço onde os estudantes vivenciem experiências de aprendizagens em Matemática semelhantes àquelas que se espera que venham proporcionar a seus alunos. Ela propõe que seja um ambiente baseado em resolução e problemas e investigação matemática. Nesse sentido, a formação não pode ter um foco em outra direção senão 'o que deve ser o ensino para esses alunos”. E corrobora: “(...) aprender matemática num curso de formação de professores é importante, mas desenvolver uma atitude de investigação e de constante questionamento em matemática, é ainda mais importante" (SERRAZINA, 2002, p. 4). Nessa mesma linha, Llinares (2013) compreende o desenvolvimento da capacidade de 'olhar profissionalmente' o ensino e a aprendizagem de matemática, como marca do processo formativo.

Conforme Serrazina (2002), são imprescindíveis momentos de investigação, construção e comunicação, envolvendo participação e reflexão nas diferentes atividades que precisam abranger diferentes níveis: 1. "de matemática na educação básica", nas quais os alunos estarão resolvendo situações que exigem conhecimentos conceituais e procedimentais; 2. "atividades de ensino envolvendo a matemática na educação básica”, envolvendo análises de situações e sequências de ensino, considerando graus de dificuldades e 3. "de atividade teórica no domínio da teoria de educação matemática" (SERRAZINA, 2002, p. 6) que inclui os estudos e pesquisas.

Devido à necessidade de ampliação formativa, na área de matemática, nos cursos de Pedagogia, é imprescindivel articular as disciplinas, os projetos de docência e de extensão, bem como, as ações de pesquisa.

\section{O PROJETO EM AÇÃO - UNIVERSIDADE E ESCOLA ENSINANDO A SER DOCENTE}

O Programa de Apoio à Licenciatura (PROLICEN), na Universidade Federal da Paraíba, desenvolve ações que favorecem a melhoria da qualidade dos cursos de Licenciatura. Através de edital anual, os professores submetem projetos para implementar ações que articulem o referido curso à docência em escolas públicas. Desde o ano de 2013, o projeto denominado: Ensinando e Aprendendo Matemática por meio de Jogos e Resolução de Problemas tem tido atuação junto aos estudantes de Pedagogia. Já passaram pelo projeto, 15 (quinze) estudantes do referido curso, entre bolsistas e voluntários, até o ano de 2018. O projeto ocorre em parceria com escolas municipais, sendo duas em cada ano, abrangendo os anos iniciais.

A abordagem metodológica assumida é a qualitativa que "trabalha com o universo de significados, motivos, (...) valores e atitudes, o que corresponde a um espaço mais profundo das relações, dos processos e dos fenômenos que não podem ser reduzidos à operacionalização de variáveis" (MINAYO, 2002), com aproximação à pesquisa participante, na qual, os estudantes e 
pesquisadores interagem no espaço escolar, buscando compreender seu funcionamento, refletindo sobre seus condicionantes e intervindo por meio de interações em sala de aula.

Nesse contexto, o projeto assume perspectivas voltadas ao ensino, à pesquisa e à extensão. $\mathrm{O}$ ensino ocorre principalmente, com a construção da docência em matemática, em turmas de anos iniciais de escolas públicas; a pesquisa, ao fomentar a investigação sobre o próprio ensino e a aprendizagem de matemática, e a extensão, por promover uma ação em espaços externos à universidade, por meio de colaboração entre profissionais das escolas e os membros do projeto.

As ações de ensino abrangem realização de diagnósticos e de sequências didáticas com jogos e resolução de problemas enquanto ferramentas metodológicas. Os jogos, como parte da cultura infantil, envolvem prazer, interação, negociação de significados e o respeito às regras. Quando se referem à Matemática, os jogos possibilitam o contato com conceitos e procedimentos da própria área, por meio de situações imaginárias e desafiadoras. Já a resolução de problemas deve ser assumida como um espaço de investigação, elaboração e validação de procedimentos de solução para diferentes situações-problema, no qual, a socialização e a reflexão permeiem todo o processo.

A cada ano, a coordenação do projeto, após selecionar os alunos (bolsistas ou voluntários), inicia um trabalho de formação para a docência em matemática, com a vivência de etapas específicas, conforme indica o quadro 1 :

\section{Quadro 1 - ETAPAS DESENVOLVIDAS NO PROJETO}

\begin{tabular}{|l|l|}
\hline \multicolumn{1}{|c|}{ No $^{-}$Etapas Desenvolvidas no Projeto PROLICEN } \\
\hline $1^{\mathrm{a}}$ & Estudos sobre o ensino e a aprendizagem de matemática \\
\hline $2^{\mathrm{a}}$ & Inserção na escola de atuação \\
\hline $3^{\mathrm{a}}$ & Observação participante \\
\hline $4^{\mathrm{a}}$ & Aplicação de diagnóstico com situações-problemas \\
\hline $5^{\mathrm{a}}$ & Sistematização dos dados (erros e acertos) para a escolha de conteúdos \\
\hline $6^{\mathrm{a}}$ & $\begin{array}{l}\text { Elaboração e aplicação de sequências didáticas envolvendo jogos e resolução de } \\
\text { problemas }\end{array}$ \\
\hline $7^{\mathrm{a}}$ & Avaliação das sequências \\
\hline $8^{\mathrm{a}}$ & Relatório final do projeto. \\
\hline
\end{tabular}

Fonte: Arquivo do Projeto: Ensinando e Aprendendo Matemática por meio de Jogos e Resolução de Problemas

Embora tenhamos etapas fixas como a inserção na escola, a observação, o diagnóstico, o planejamento e a realização de sequências didáticas, a cada ano, as atividades são sempre reelaboradas, uma vez que os enfoques variam e os estudantes graduandos são outros, necessitando desenvolver capacidades e habilidades que o projeto exige, como desenvolver metodologias inovadoras no trabalho pedagógico. Até o ano de 2018, o projeto abrangeu os eixos de Números e Operações (campos aditivo e multiplicativo) e Grandezas e Medidas. As ações em sala de aula têm duração diária de 40 a 50 minutos, sendo dois dias por semana, nos meses de julho a novembro. 
Para o alcance do objetivo de problematizar as possibilidades de se formar para a docência em matemática, num curso de Pedagogia, analisaremos um relato de uma sequência didática vivenciada no projeto e os dados de um questionário, aplicado aos estudantes-graduandos que participaram do projeto.

O relato versará sobre uma vivência com o conteúdo de multiplicação, abrangendo o uso de jogos e a resolução de problemas em uma turma do $5^{\circ}$ ano, em 2017. O questionário foi composto de duas partes: de informações relativas aos participantes e de avaliação do projeto enquanto aporte à formação e ao trabalho docente. Os dados foram organizados em categorias como perfil dos participantes, contribuição do projeto para a formação e atuação profissional, bem como, dificuldades vivenciadas no projeto.

\section{O PROJETO PROLICEN E A FORMAÇÃO MATEMÁTICA DE PROFESSORES DE ANOS INICIAIS}

\section{a) Sequência didática com jogos e resolução de problemas no $5^{\circ}$ ano}

A partir da atividade diagnóstica, identificou-se a necessidade de explorar com a turma do $5^{\circ}$ ano $A$, a multiplicação. Foi organizada uma sequência didática com os objetivos: compreender os significados da multiplicação, principalmente de área; resolver situações-problema envolvendo significados da multiplicação e relacionar diferentes representações de multiplicação. Para tanto, foram propostas diferentes atividades, dentre as quais apresentamos: a vivência de um jogo - 'conquista de terrenos', a aplicação de uma atividade de resolução de problemas e um ditado da multiplicação.

A vivência do jogo foi iniciada com a formação de grupos, entrega de material (dois dados, papel quadriculado e lápis de cor) e explicação das regras. No jogo, os participantes deveriam lançar dois dados e, com os pontos obtidos, realizar uma multiplicação, traçando no papel quadriculado, o terreno equivalente. Por exemplo: se obtivesse 6 e 3 nos dados, traçar no quadriculado um terreno 6 por 3 (com seis linhas e três colunas ou o inverso), cercando dezoito quadrados. Os alunos deveriam pintar/assinalar esses "terrenos conquistados", para diferenciar dos demais. Venceria o aluno que obtivesse mais 'terrenos'. No final, após a análise dos registros dos alunos, percebeu-se que eles realizaram a multiplicação corretamente, porém não traçaram os terrenos no quadriculado de forma adequada. Eles não haviam compreendido que tanto o resultado da multiplicação quanto a sua representação no quadriculado, eram importantes. Diversos alunos não seguiram os pontos obtidos nos dados como referência para traçar os terrenos (Fig. 1), preocupando-se apenas com o resultado da multiplicação. Foi também possível perceber que alguns consultaram a tabuada, conforme indica a Fig. 2, mais adiante. 
Figura 1 - REGISTRO DOS ALUNOS

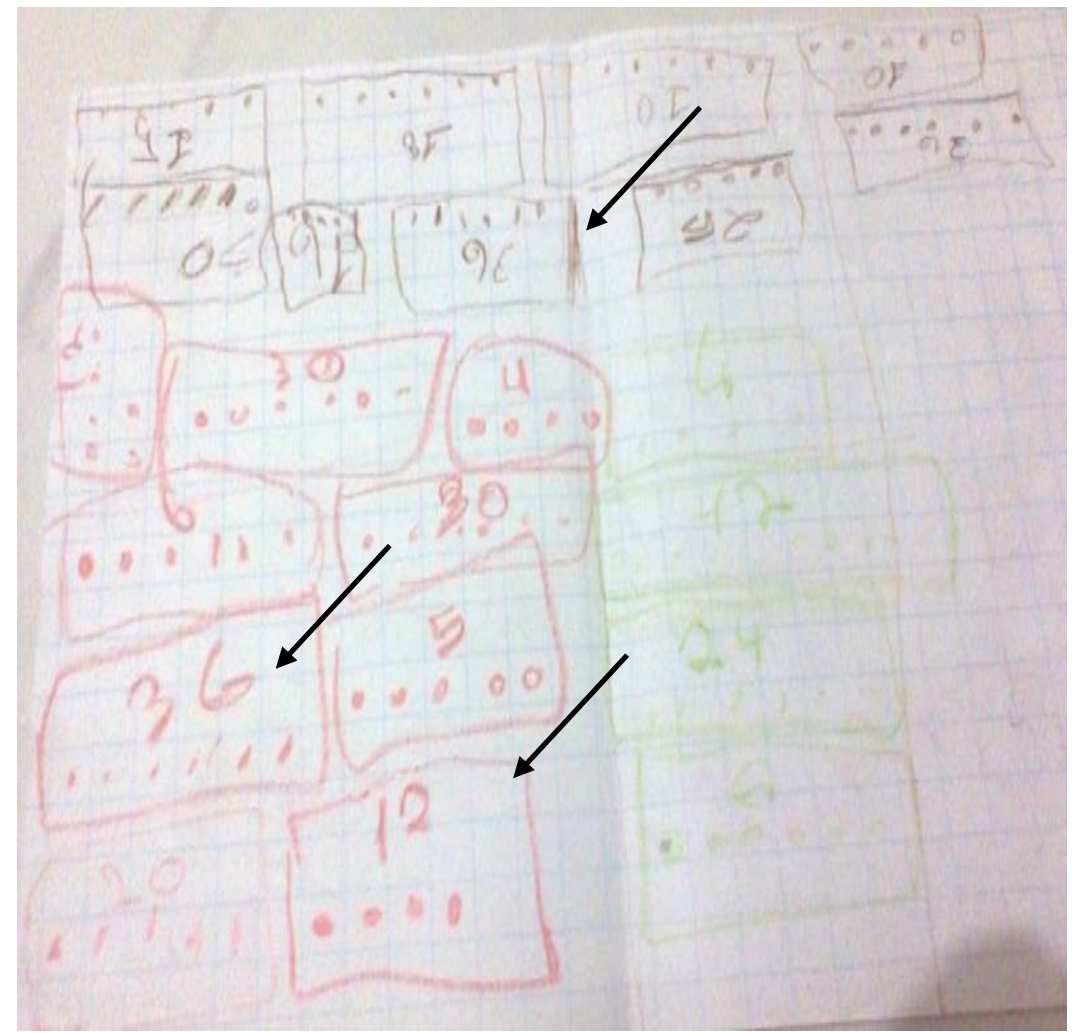

Fonte: Dados do Projeto PROLICEN - 2017

Figura 2 - JOGO DA CONQUISTA - 5 ANO

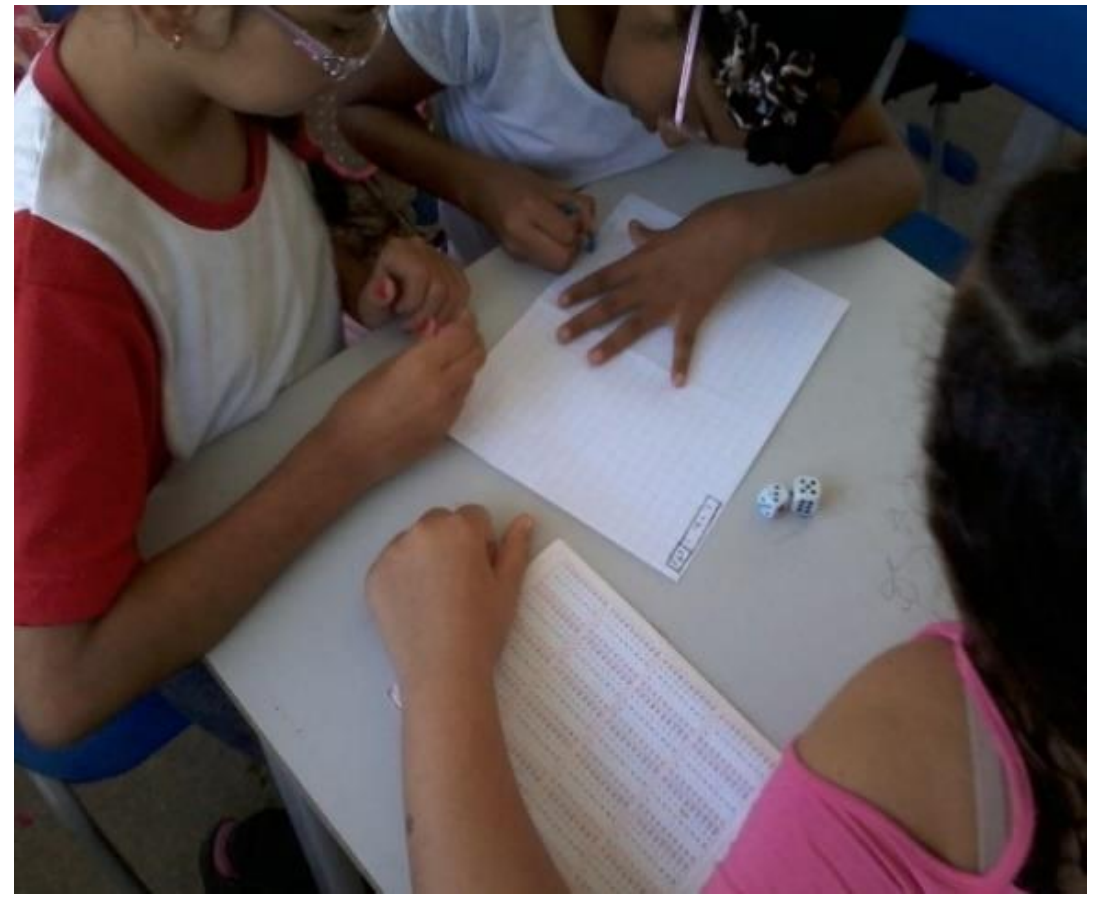

Fonte: Dados do Projeto PROLICEN - 2017 
Embora tenha ocorrido essa situação, no dia seguinte, aplicou-se uma atividade escrita que explorava a compreensão do campo multiplicativo e do jogo da conquista. Uma das tarefas era: "Represente no quadriculado abaixo, um terreno de área 24, de diferentes maneiras". Mesmo com explicações, muitos alunos consideraram apenas o total 24 , pintando essa quantidade de diferentes maneiras, porém distanciando-se da ideia dos "terrenos" solicitados, enquanto área de retângulos. Vejamos o registro do aluno 7, na Fig. 3:

Figura 3 - REGISTRO DA ATIVIDADE - ALUNO 7

2. Represente no quadriculado ahaiko, um ierreno de area 24 , de diferentes maneiras:

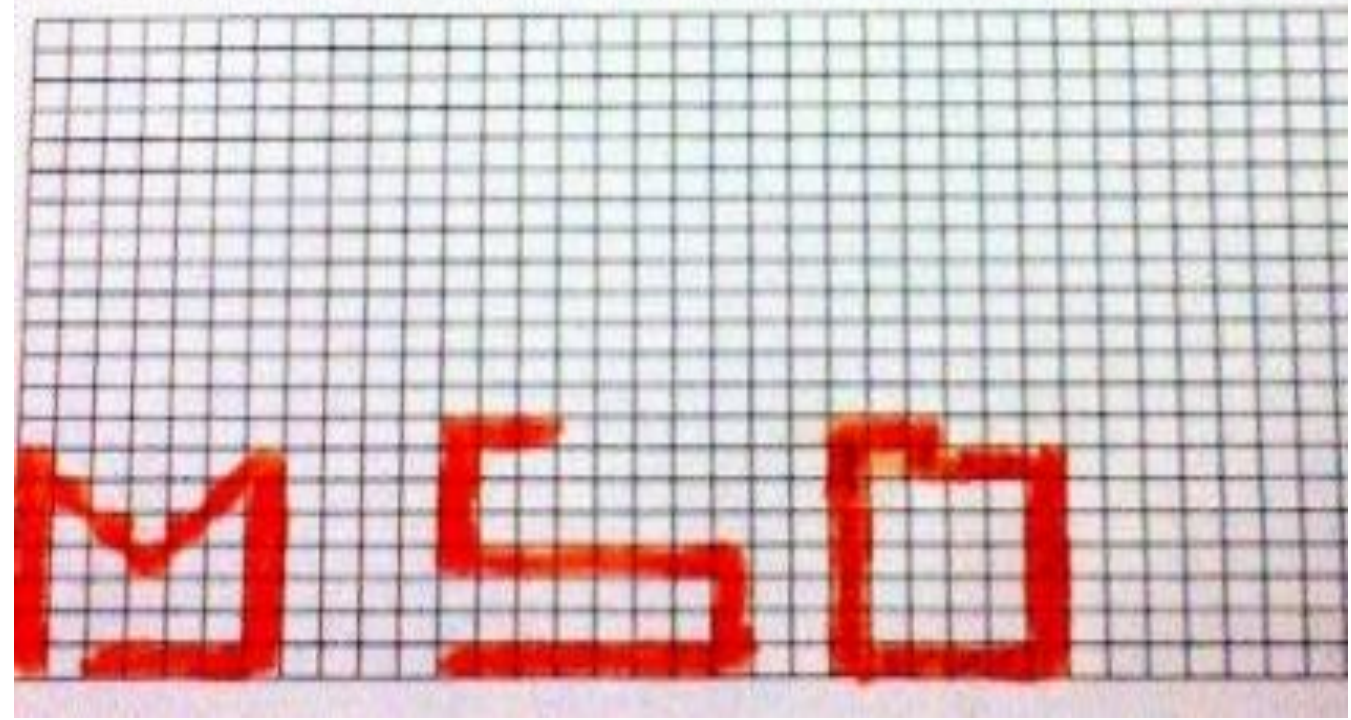

Fonte: Dados do Projeto PROLICEN - 2017

Mediante às dificuldades encontradas, houve um redirecionamento na sequência e, na semana seguinte, foi promovido o mesmo 'jogo da conquista', porém, com algumas alterações. Dividiu-se a turma em três equipes, foi anexado um cartaz quadriculado no quadro, em seguida, um representante de cada equipe deveria vir até o centro da sala, retirar duas tampinhas (com números de 1 a 9), realizar uma multiplicação e representar no quadriculado, um terreno correspondente (Fig. 4). O grupo que conseguisse acertar, ganharia 1 ponto para a sua equipe. Neste dia, as equipes se envolveram mais no jogo, mostrando-se centradas, pois sabiam que o acerto resultaria em ganho para a sua equipe. 
Figura 4 - REGISTRO DOS TERRENOS NO CARTAZ

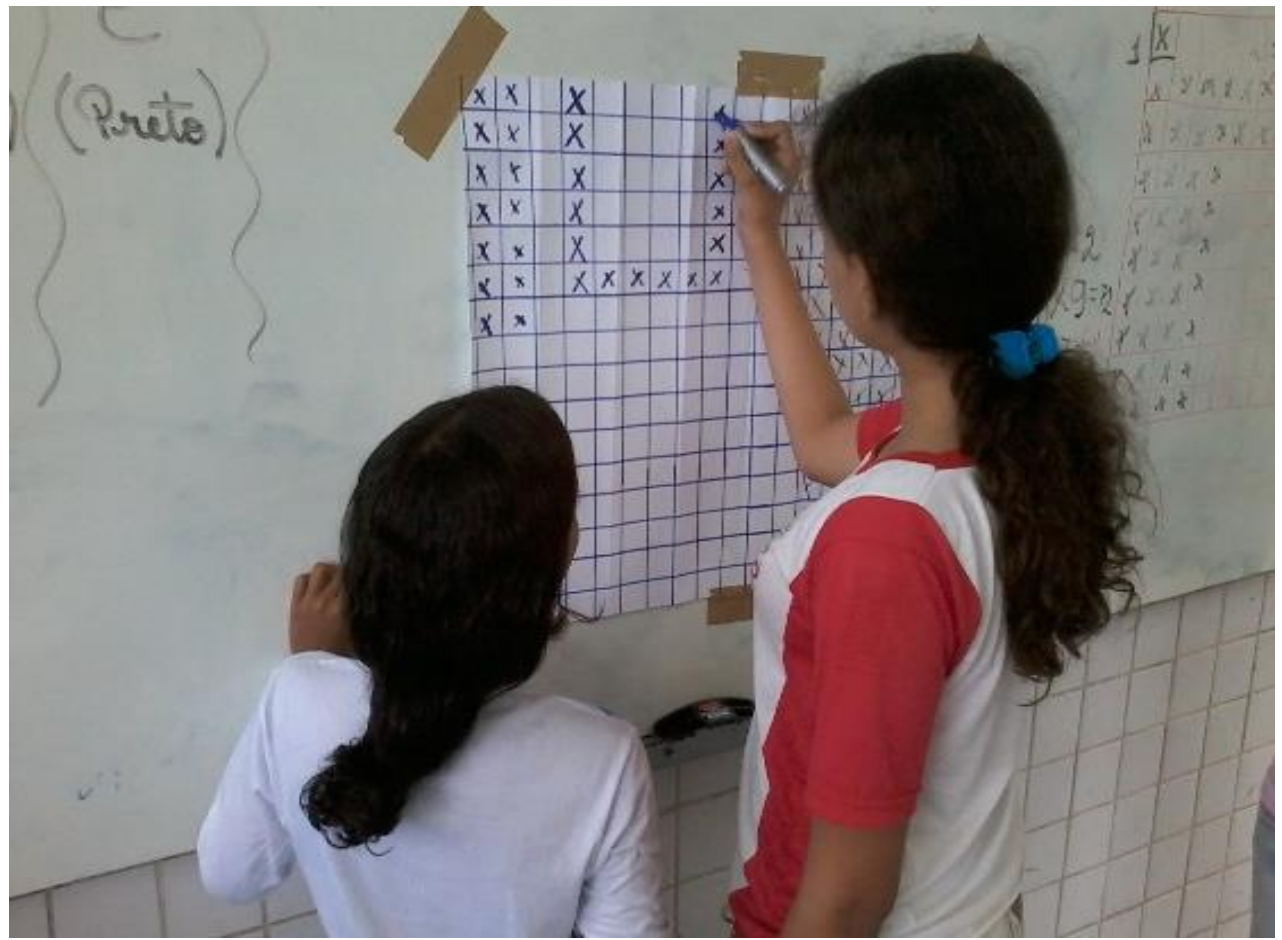

Fonte: Dados do Projeto PROLICEN - 2017

No dia seguinte, foi feito o ditado da multiplicação que consistia em ditar diferentes sentenças multiplicativas $(6 \times 5,8 \times 3,6 \times 8,4 \times 6 \ldots)$ para que os alunos representassem em sua folha quadriculada, relacionando-as aos terrenos do jogo. Essa atividade também foi bastante positiva e, quase todas as crianças, acertaram. Ver o registro do aluno 15 do $5^{\circ}$ Ano, na Fig. 5.

Figura 5 - REGISTRO DO ALUNO 15, DO $5^{\circ}$ ANO A - DITADO DA MULTIPLICAÇÃO

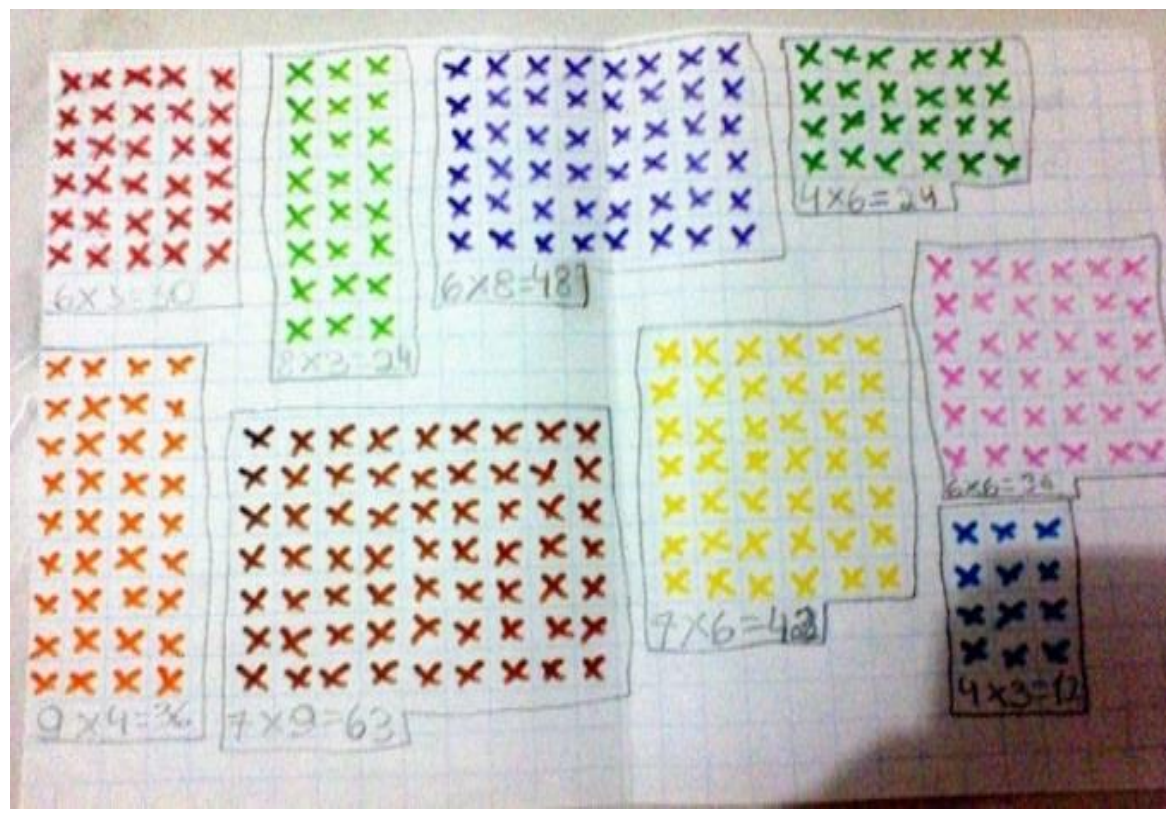

Reflexão e Ação [ISSN 1982-9949]. Santa Cruz do Sul, v. 29, n. 1, p. 114-132, jan./abr. 2021 https://online.unisc.br/seer/index.php/reflex/index 
$\mathrm{Na}$ semana seguinte, foi realizado uma outra versão do jogo da Conquista, desafiando-os a pensar de forma inversa. Com 'terrenos' já traçados, caberia às equipes comparar a sentença multiplicativa ao terreno equivalente. A equipe vencedora seria a que obtivesse mais quadradinhos, ou seja, o maior terreno. Em sua vez, cada equipe, sorteava uma sentença e, em seguida, encontrava o retângulo com a área correspondente. Adiante, colava-a no quadro no espaço destinado à sua equipe, conforme indica a figura 6 . Foram formadas três equipes que jogaram duas partidas. Ao final do jogo, cada equipe contou os terrenos obtidos por meio da quantidade de quadradinhos, realizando a soma entre os produtos de cada rodada.

\section{Figura 6 - ANEXANDO O TERRENO NO QUADRO}

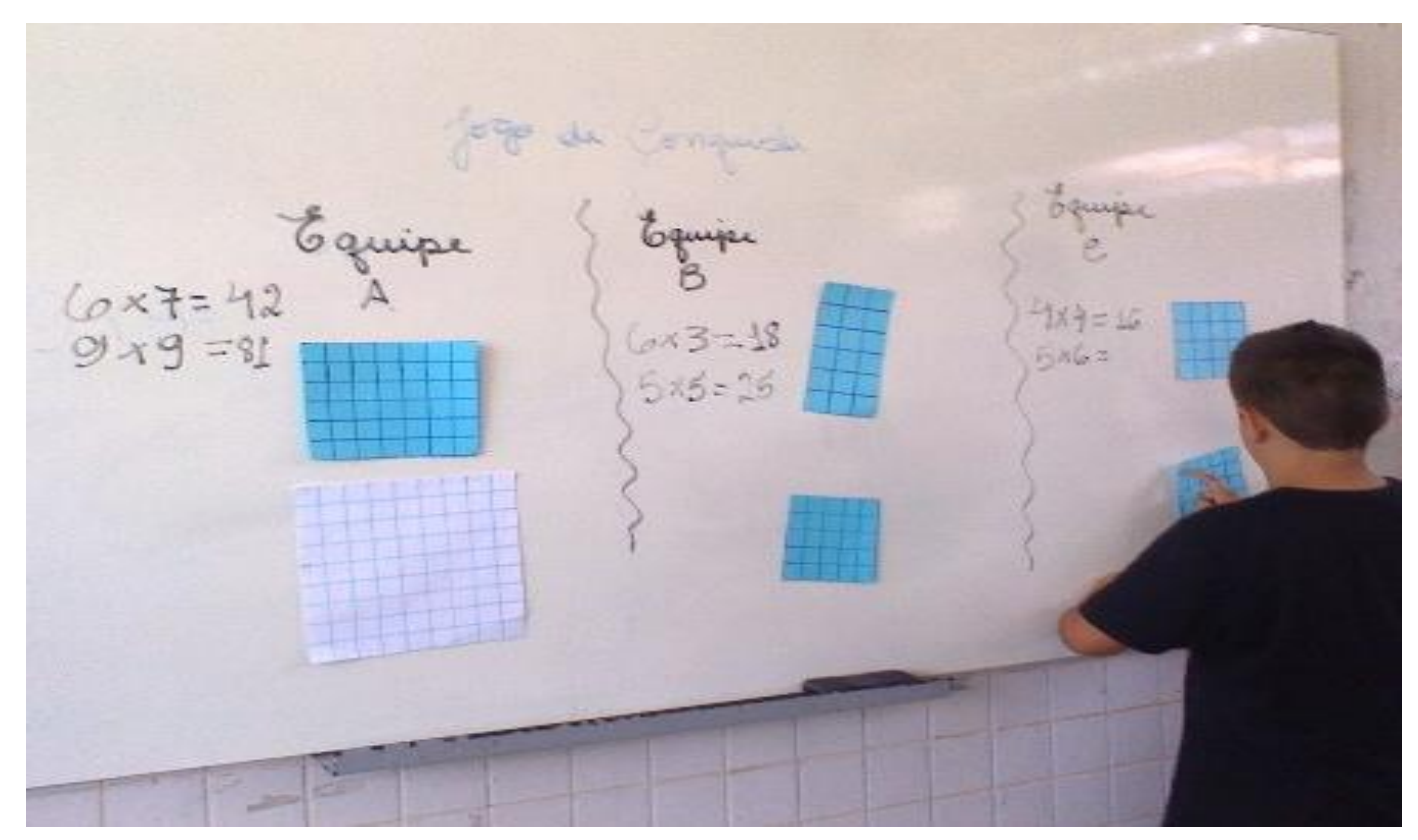

Fonte: Dados do Projeto PROLICEN - 2017

Por meio da procura do terreno, os alunos estabeleciam relações de estimativa, visto que ao ser sorteada a multiplicação 9x9, eles não escolhiam qualquer terreno, mas sim os maiores, pois já sabiam que esta multiplicação equivaleria a uma área grande. A sequência didática foi finalizada com outra atividade escrita, na qual era solicitado que os alunos resolvessem situações-problema, como: "Pedrinho e Gustavo estavam jogando o Jogo dos Terrenos com números maiores. Se Pedrinho sorteou os números 9 e 6 e Gustavo sorteou 8 e 8 . Quem ganhou a rodada? Por quê?

O que se destaca deste relato é o processo de construção de atividades pedagógicas a partir das demandas dos alunos, seus registros e erros, indicando a necessidade de replanejar/retomar questões, criando novas possibilidades para um mesmo jogo. No início da sequência, com o 'jogo da conquista' nos grupos, esperou-se que por serem alunos do $5^{\circ}$ ano, já tinham consolidado alguns conceitos e procedimentos, o que não se comprovou. 
No relato, é possível identificar a experimentação de processos, como organização de conteúdos; análise e interpretação de produções dos alunos e o gerenciamento do conteúdo em sala de aula, propostos por Llinares e Fernández (2012). Embora de forma inicial, os graduandos analisaram estratégias dos alunos, avaliando o desempenho e refletiram sobre a gradação de dificuldades entre as atividades propostas. A partir de leituras sobre o campo multiplicativo, reelaboraram tarefas e jogos, ampliando desafios e favorecendo o alcance dos objetivos. Contaram ainda com o apoio da coordenação do projeto e da professora da sala que acompanhou a sequência didática, apoiando na gestão da turma. Houve aprendizagens variadas, conforme Shulman (2014), principalmente, conhecimento pedagógico geral, com o gerenciamento da turma; conhecimento pedagógico do conteúdo, com as vivências, envolvendo o jogo matemático, as problematizações e as tarefas de resolução de problemas; e o conhecimento sobre os alunos, suas dificuldades e potencialidades.

\section{b) $\mathrm{O}$ que dizem os estudantes sobre o projeto}

Foi aplicado um questionário aos 15 participantes do projeto, no mês de novembro de 2018, porém a devolutiva foi de 8 (oito) componentes, dentre eles, cinco estudantes já concluintes (1, 2, 3, 4 e 5) e três, ainda cursando Pedagogia (6, 7 e 8), conforme o quadro 2 :

\section{Quadro 2 - PERFIL DAS PARTICIPANTES}

\begin{tabular}{|c|c|c|c|c|c|}
\hline Nome & Sexo & $\begin{array}{l}\text { Ano de } \\
\text { atuação }\end{array}$ & $\begin{array}{c}\text { Tempo } \\
\text { de } \\
\text { atuação }\end{array}$ & $\begin{array}{c}\text { Produção } \\
\text { de TCC na } \\
\text { área }\end{array}$ & Atuação Profissional \\
\hline Estudante 1 & $\mathrm{~F}$ & 2015 & 4 meses & Sim & $\begin{array}{l}\text { Programa Mais Alfabetização } \\
\text { (rede pública) }\end{array}$ \\
\hline Estudante 2 & $\mathrm{~F}$ & 2016 & $\begin{array}{l}10 \\
\text { meses }\end{array}$ & Sim & $\begin{array}{l}\text { Professora de anos iniciais (rede } \\
\text { privada) }\end{array}$ \\
\hline Estudante 3 & $\mathrm{~F}$ & $\begin{array}{l}2016 \text { e } \\
2017\end{array}$ & $\begin{array}{l}20 \\
\text { meses }\end{array}$ & Sim & $\begin{array}{l}\text { Professora de Educação Infantil } \\
\text { (rede privada) }\end{array}$ \\
\hline Estudante 4 & $M$ & 2017 & $\begin{array}{l}10 \\
\text { meses }\end{array}$ & Sim & $\begin{array}{l}\text { Programa Mais Alfabetização } \\
\text { (rede pública) }\end{array}$ \\
\hline Estudante 5 & $\mathrm{~F}$ & 2017 & $\begin{array}{l}10 \\
\text { meses }\end{array}$ & Sim & - \\
\hline Estudante 6 & $\mathrm{~F}$ & 2017 & $\begin{array}{l}10 \\
\text { meses }\end{array}$ & Não & - \\
\hline Estudante 7 & $\mathrm{~F}$ & 2018 & $\begin{array}{l}10 \\
\text { meses }\end{array}$ & $\begin{array}{l}\text { Em } \\
\text { elaboração }\end{array}$ & - \\
\hline Estudante 8 & $\mathrm{~F}$ & 2018 & 10 & $\mathrm{Em}$ & - \\
\hline
\end{tabular}




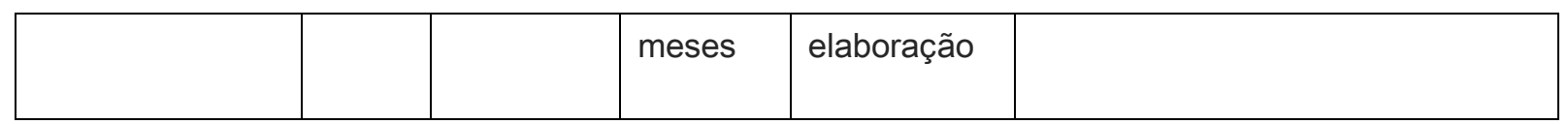

Fonte: Questionário aplicado aos participantes do Projeto

Dos participantes que responderam o questionário, apenas a Estudante 1, ficou menos de 10 meses no projeto e a Estudante 3, permaneceu dois anos seguidos.

Quanto à produção do Trabalho de Conclusão de Curso, apenas a Estudante 6 não está investigando o ensino de Matemática. Os outros estudantes ou já concluíram o TCC com temas que convergiam com o projeto ou estão ainda em elaboração.

Embora os alunos de Pedagogia apresentem certo distanciamento da área de Matemática (CARVALHO, 1991; NACARATO; MENGALI; PASSOS, 2009), alguns alunos têm se envolvido a tal ponto que chegam a elaborar o TCC, versando sobre a área de educação matemática, ampliando os estudos, o que vem a contribuir ainda mais para a formação deste profissional. Os últimos três trabalhos produzidos a partir do projeto, apresentados em 2017, foram: 'Educação Financeira na Escola do Campo: a importância de jogos matemáticos em sua aprendizagem' (E3); 'Jogos Matemáticos e Resolução de Problemas no Campo Aditivo - Qual a contribuição?' (E3 e E5) e 'A Resolução de Problemas como Ferramenta no Ensino do Campo Multiplicativo' (E4).

A segunda parte do questionário buscou saber sobre a contribuição do projeto para a formação e atuação profissional, bem como, acerca dos aspectos negativos. Do grupo que respondeu o instrumento, dois estão trabalhando em programas em escolas públicas e dois, na rede privada.

Sobre a contribuição do projeto para a formação profissional, algumas respostas evidenciaram aspectos mais gerais, como: "para uma formação de qualidade" (3), "para conhecer propostas facilitadoras no processo de ensino e aprendizagem" (4); e outras mais específicas, conforme os Estudantes 1 e 8:

\footnotetext{
Contribuiu bastante através das leituras dos teóricos na formação pedagógica, através dos debates e orientações passadas pela nossa coordenadora e pela experiência adquirida em sala de aula (...) (Estudante 1).

A articulação entre a teoria e a prática, fez com que as discussões ganhassem mais sentido, colaborando com os conhecimentos construídos nas disciplinas de graduação (Estudante 8).
}

Os respondentes referiram-se aos estudos realizados, ressaltando os saberes científicos e pedagógicos apreendidos no projeto, na relação com o espaço profissional da escola que possibilita uma articulação entre teoria e prática. Outros participantes, evidenciaram aspectos da gestão da sala de aula, da interação com os alunos e a escola pública, e de compreensão sobre processos de ensinar a disciplina, como os Estudantes 5, 7 e 8:

(...) na melhora da postura dentro de sala, aprender a lidar com situações que fogem ao planejado, tentar ser sempre criativo nas atividades, aprender a se comunicar com os alunos tanto no saber falar quanto no saber ouvir e entender que cada indivíduo é diferente do outro, no que diz respeito às aprendizagens. (Estudante 5)

(...) a experiência de observar a dinâmica da sala de aula, as dificuldades do ensino da Matemática, como se dá a relação professor-aluno e a vivência no contato com o ambiente no qual se vai atuar (Estudante 7). 
(...) proporcionou vivenciar os desafios e as dinâmicas que abrangem a escola, bem como, a sala de aula. Enquanto graduanda, ele promoveu o meu primeiro contato com o espaço escolar, o convívio com professores experientes, a pesquisa por novas metodologias no ensino da matemática (Estudante 8).

Vê-se nas respostas, uma intersecção entre a formação e a atuação docente. Ao falarem do que o projeto contribuiu, alguns já se percebem na função de professores. Referenciando-se nos saberes docentes, a formação inicial tem caráter mais complexo do que a visão 'aplicacionista' do conhecimento, a qual entende que deve ocorrer uma condução direta dos conhecimentos ensinados na universidade para as salas da educação básica. As aprendizagens no projeto ultrapassam as leituras dos textos na academia, incluem aquelas construídas a partir da interação viva, com alunos reais, vivenciando-se o inusitado e o imprevisto, lidando com a heterogeneidade das turmas e testando a viabilidade de algumas metodologias de ensino. Os estudos e reflexões elaborados na universidade são testados ou ratificados pela imersão nas salas de aula.

Quanto à contribuição para o trabalho docente, ressaltaram tarefas assumidas pelo professor, incluindo a interação com a turma: "através da experiência adquirida em sala de aula e da elaboração das atividades para aplicação do projeto (E1); (...) as experiências vivenciadas estão servindo de base, como por exemplo: para o dia a dia da sala de aula, o planejamento das atividades e na relação com os alunos (E3)". A estudante 7, embora não esteja trabalhando em escola, listou diferentes aprendizagens que servirão de base para sua atuação profissional:

\begin{abstract}
temos que ter sempre um plano B; que os alunos podem perceber e entender as atividades de uma forma diferente do que foi explicado, e não quer dizer que estão errados; que o jogo quando aplicado de maneira pedagógica, é um forte aliado do professor; não se pode ir para a sala de aula com a cabeça formatada; que o jogo proporciona uma experiência prática do conteúdo e é uma forma de resolver problemas (Estudante 7).
\end{abstract}

Esta resposta indica a construção de saberes sobre a gestão da sala de aula, a compreensão de processos de construção de conceitos pelos alunos, a importância do planejamento e contribuições das metodologias do jogo e da resolução de problemas, abrangendo diferentes conhecimentos propostos por Shulman (2014).

Sobre as dificuldades, as respostas se referiram mais à gestão da sala de aula, à organização dos alunos, ao desinteresse demonstrado em algumas vivências e, também, aspectos estruturais da escola, principalmente quanto à organização das turmas e sua heterogeneidade de níveis de conhecimento. As falas a seguir representam esses pontos:

Minha maior dificuldade foi de fazer com que todos alunos prestassem atenção nas regras dos jogos, uma vez que a indisciplina predominava a aula e, muitas vezes, a professora que ficava na sala não conseguia dominar os alunos (Estudante 2).

Minha maior dificuldade foi em relação à gestão da turma e de conseguir envolver todos os alunos nas vivências, pois vez ou outra, alguns se recusavam a participar. Outro aspecto foram os diferentes níveis de aprendizagem, pois enquanto alguns compreendiam o que estava sendo trabalhado, outros demandavam maior tempo para chegar naquela compreensão (Estudante 8). 
A gestão de sala de aula aparece de maneira significativa, uma vez que além de inexperientes, os estudantes de Pedagogia estão na escola em momentos pontuais. Por outro lado, eles promovem atividades de jogos e resolução de problemas que alteram o contrato didático da sala de aula, exigindo a pactuação de novos combinados e seu cumprimento. Embora os jogos tenham um forte apelo à motivação e à participação dos alunos, em todos os anos do projeto, os bolsistas lidam com grupos de crianças que não se interessam de imediato pelos jogos matemáticos. A hipótese é que o jogo exige reflexão e resolução de problemas, o que nem sempre é desenvolvido em aulas de matemática.

\section{CONSIDERAÇÕES FINAIS}

Tomando como referência as proposições discutidas, acerca dos conhecimentos necessários à docência, conclui-se que há muito ainda a ser feito, principalmente porque o alcance do projeto, em termos numéricos, não é grande. Contudo, para os granduandos participantes, os resultados têm indicado que as ações promovidas ampliaram a formação docente em matemática, ao proporcionar experiências de aprendizagens acerca do campo profissional e no espaço profissional de escolas públicas. Ter a possibilidade de aproximar-se e realizar ações docentes de observação, planejamento, preparação de materiais, promoção de aulas e avaliação, é antes de tudo, favorecer o desenvolvimento do 'olhar profissional', discutido por Llinares (2003). Eles vivenciaram uma práxis pedagógica, embasada na ação - reflexão - ação, estudando, analisando, ensinando, interagindo e refletindo sobre suas ações (que deram certo ou não), no sentido de proporcionar compreensão matemática às crianças.

Da realidade formativa para a docência, na Pedagogia, emergimos duas reflexões: a relação direta entre formação e inserção no campo profissional , uma vez que embora a formação inicial não seja conclusiva, ela deve consolidar conhecimentos que habilitem o egresso do curso em seu exercício profissional; e que as demandas para essa formação inicial estão cada vez maiores, visto que os sistemas de ensino cobram impactos e mais resultados do processo de escolarização. Que os cursos de licenciatura possam dialogar mais com tais demandas, buscando diferentes alternativas para respondê-las, em articulação com as próprias escolas.

\section{REFERÊNCIAS}

1. BRASIL. CNE. Lei de Diretrizes e Bases da Educação Nacional. Lei 9394/96. Conselho Nacional de Educação, 2016.

2. BRASIL. CNE. Resolução CNE/CP n 1, de 15 de maio de 2006. Conselho Nacional de Educação Conselho Pleno, 2006.

3. BRASIL. INEP. Resultados da Prova Brasil de 2017 - Brasil, Estados e Municípios. Disponível em http://portal.inep.gov.br/educacao-basica/saeb/resultados 
4. BRASIL. INEP. Relatório SAEB/ANA 2016: panorama do Brasil e dos estados. Brasília: Instituto Nacional de Estudos e Pesquisas Educacionais Anísio Teixeira, 2018.

5. CARVALHO, Dione L. de. Metodologia do Ensino da Matemática. São Paulo: Cortez, 1991.

6. COSTA, Jaqueline de M.; PINHEIRO, Nilceia A. M. e COSTA, Ercules. A formação para matemática do professor de anos iniciais. Ciênc. Educ., Bauru, v. 22, n. 2, p. 505-522, 2016.

7. CURI, Edda. A Matemática e os Professores dos Anos Iniciais. São Paulo: Musa Editora, 2005.

8. D’AMBROSIO, Beatriz. S. Conteúdo e metodologia na formação de professores. In: FIORENTINI, D. e NACARATO, A. M. (Orgs). Cultura, formação e desenvolvimento profissional de professores que ensinam Matemática: investigando e teorizando a partir da prática. São Paulo: Musa Editora; Campinas, SP: GEPFPM-PRAPEM-FE/UNICAMP, 2005.

9. GATTI, Bernadete. A. O Curso de Licenciatura em Pedagogia: dilemas e convergências. EntreVer, Florianópolis, v. 2, n. 3, p. 151-169, jul./dez. 2012.

10. LIBÂNEO, José C. Adeus Professor, Adeus Professora? Novas exigências educacionais e profissão docente. $4^{\mathrm{a}}$ edição. São Paulo: Cortez, 2000.

11. LIBÂNEO, José C. Diretrizes Curriculares da Pedagogia: Imprecisões Teóricas e Concepção Estreita da Formação Profissional de Educadores. Educ. Soc., Campinas, vol. 27, n. 96 - Especial, p. 843-876, out. 2006.

12. LIMA, Simone M. e CARVALHO, Ademar de L. Um estudo sobre a formação do pedagogo e o Ensino da Matemática nos Anos Iniciais do Ensino Fundamental. Série-Estudos - Periódico do Programa de Pós-Graduação em Educação da UCDB. Campo Grande, MS, n. 37, p. 201-214, jan./jun. 2014.

13. LLINARES, Salvador. e FERNÁNDEZ, Ceneida. Formación de Professores de Matemáticas relación entre teorias sobre el aprendizaje del professor y diseño de entornos de aprendizaje. In: SILVA, A. C.; CARVALHO, M. e RÊGO, R. G. (Orgs.) Ensinar Matemática: formação, investigação e práticas docentes. Cuiabá, EdUFMT, 2012.

14. LLINARES, Salvador. El desarrollo de la competencia docente "mirar profesionalmente" la enseñanza-aprendizaje de las matemáticas. Educar em Revista, Curitiba, Brasil, n. 50, p. 117-133, out./dez. 2013. Editora UFPR 
15. MATOS, Diego de V. e LARA, Isabel C. M. de. Formação de Professores dos Anos Iniciais e o Ensino de Matemática: Mapeamento de algumas Produções Brasileiras. Abakós, Belo Horizonte, v. 5, n. 1, p. 48-62, nov. 2016-ISSN:2316-9451.

16. MINAYO, Maria Cecília de S. (Org.). Pesquisa social: teoria, método e criatividade. $21^{\mathrm{a} e d}$. Petrópolis, RJ: Vozes, 2002.

17. MOREIRA, Antônio F. B. e CANDAU, Vera. Indagações sobre currículo: currículo, conhecimento e cultura; Jeanete Beauchamp, Sandra Denise Pagel, Aricélia Ribeiro do Nascimento (Org.). Brasília: Ministério da Educação, Secretaria de Educação Básica, 2007.

18. NACARATO, Adair M. A Formação Matemática das Professoras das Séries Iniciais: a escrita de si como prática de formação. Bolema, Rio Claro (SP), v. 23, n 37, p. 905 a 930, dezembro 2010.

19. NACARATO, Adair M; MENGALI, Brenda L. da S.; PASSOS, Carmem L. B. A Matemática nos Anos Iniciais do Ensino Fundamental - tecendo fios do ensinar e do aprender. Belo Horizonte: Autêntica Editora, 2009.

20. SERRAZINA, Maria de L. Conhecimento matemático para ensinar: papel da planificação e da reflexão na formação de professores. Revista Eletrônica de Educação. São Carlos, SP: UFSCar, v. 6, no. 1, p.266-283, mai. 2012. http://www.reveduc.ufscar.br.

21. SERRAZINA, Lurdes. A formação para o ensino da Matemática: Perspectivas futuras. 2002. https://www.researchgate.net/profile/Lurdes_Serrazina. Acesso em 10 de março de 2019.

22. SHULMAN, Lee. Conhecimento e ensino: fundamentos para a nova reforma. In: Cadernos CENPEC, São Paulo, v.4, n.2, p.196-229, dez. 2014. (Tradução de Leda Beck e revisão técnica de Paula Louzano).

SILVA, Vantielen da S. e BURAK, Dionísio. A Formação de Pedagogos para o Ensino de Matemática nos Anos Iniciais: Alguns Apontamentos a Partir de Dissertações e Teses. In: Anais do XII Encontro Nacional de Educação Matemática. Educação Matemática na Contemporaneidade: desafios e possibilidades São Paulo - SP, 13 a 16 de julho de 2016. http://dx.doi.org/10.18764/2178-2229.v24nespecialp159-175

24. TARDIF, Maurice. Saberes profissionais dos professores e conhecimentos universitários Elementos para uma epistemologia da prática profissional dos professores e suas consequências em relação à formação para o magistério. Revista Brasileira de Educação. Jan/Fev/Mar/Abr, 2000. $\mathrm{N} \circ 13$ 


\section{Maria Alves de Azerêdo}

Considerando que a formação matemática na Pedagogia é incipiente, nosso objetivo foi problematizar as contribuições de um projeto voltado à licenciatura que busca efetivar uma articulação com escolas públicas, ampliando a formação inicial. Embasando-se em autores que discutem formação docente em matemática e na pesquisa qualitativa, analisou-se um relato de uma sequência didática sobre multiplicação, numa turma de $5^{\circ}$ ano e dados de um questionário aplicado aos graduandos. Concluiuse que as atividades do projeto têm ampliado a formação docente em matemática, ao possibilitar a vivência em salas de aula, tendo a escola pública também como espaço formativo, articulando teoria e prática.

\section{Como citar este documento:}

AZERÊDO, Maria Alves de. A FORMAÇÃO MATEMÁTICA NA PEDAGOGIA: A ARTICULAÇÃO UNIVERSIDADE-ESCOLA COMO CAMINHO FORMATIVO. Reflexão e Ação, Santa Cruz do Sul, v. 29, n. 1, p. 114-132, jan. 2021. ISSN 1982-9949. Acesso em: doi: http://dx.doi.org/10.17058/rea.v29i1.13780 